\title{
One-Year Remission Rate of Chronic Headache Comparing Video and Face-to-Face Consultations by Neurologist: Randomized Controlled Trial
}

Svein Ivar Bekkelund, MD, PhD; Kai Ivar Müller, MD, PhD

Department of Clinical Medicine, The Arctic University of Norway, Troms $\emptyset$, Norway

\section{Corresponding Author:}

Svein Ivar Bekkelund, MD, PhD

Department of Clinical Medicine

The Arctic University of Norway

Hansine Hansens veg 18

Tromsø, 9037

Norway

Phone: 4790185090

Email: svein-ivar.bekkelund@uit.no

\section{Abstract}

Background: Chronic headache causing severe headache-related disability for those affected by the disease is under- or misdiagnosed in many cases and therefore requires easy access to a specialist for optimal health care management.

Objective: The goal of the research is to determine whether video consultations are noninferior to face-to-face consultations in treating chronic headache patients referred to a specialist in Northern Norway.

Methods: Patients included in the study were recruited from general practice referrals to a specialist at a neurological department in Northern Norway (Troms $\varnothing$ ) and diagnosed according to the International Headache Society classification system. In a randomized controlled design, the 1-year remission rate of chronic headache (change from $\geq 15$ to $<15$ headache days per month during the last 3 months), patient satisfaction with a specialist consultation, and need for follow-up consultations by general practitioners were compared between groups consulted by video and face-to-face in a post hoc analysis. Data were collected by interview (baseline) and questionnaire (follow-up).

Results: From a baseline cohort of 402 headache patients consecutively referred from general practice to a specialist over 2.5 years, $58.0 \%$ (233/402) were classified as chronic headache and included in this study. Response rates were 71.7\% (86/120) in the video group and $67.3 \%$ (76/113) in the face-to-face group. One-year remission from chronic headache was achieved in $43.0 \%$ (37/86) in the video group and 39.5\% (30/76) in the face-to-face group $(P=.38)$. Patient satisfaction with consultations were $86.5 \%$ (32/37; video) and 93.3\% (28/30; face-to-face; $P=.25)$. A total of 30\% (11/37) in the video group and 53\% (16/30) in the face-to-face group consulted general practitioners during the follow-up period $(P=.03)$, and median number of consultations was 1 (IQR 0-13) and 1.5 (IQR 0-15), respectively $(P=.19)$.

Conclusions: One-year remission rate from chronic headache was about $40 \%$ regardless of consultation form. Likewise, patient satisfaction with consultation and need for follow-up visits in general practice post consultation was similar. Treating chronic headache patients by using video consultations is not inferior to face-to-face consultations and may be used in clinical neurological practice.

Trial Registration: ClinicalTrials.gov NCT02270177; https://clinicaltrials.gov/ct2/show/NCT02270177

(J Med Internet Res 2021;23(12):e30151) doi: 10.2196/30151

\section{KEYWORDS}

chronic headache; remission; video consultation; telemedicine; eHealth; digital consultation; consultation; treatment; follow-up; $\mathrm{RCT}$; randomized controlled trial 


\section{Introduction}

\section{Background}

Chronic headache is a condition that transforms from primary headaches and is mainly identified as chronic migraine and chronic tension-type headache affecting about $1 \%$ to $2 \%$ and $2 \%$ of the population, respectively [1-3]. Lack of diagnostic biomarkers is a major challenge, and the chronic headache diagnosis (presence of headache 15 or more days per month for the last 3 months) is made by using a structured interview that relies on a validated diagnostic classification system [4]. Headache burden in the population is high and has not improved at the population level over time [5,6]. Preferably, headache should be correctly classified and treated at earliest to minimize risk of becoming chronic and development of associated conditions such as psychiatric symptoms [7], comorbid pain [8], increased costs for patients and the society [9], and impaired work performance [10], which are some known consequences that may burden chronic headache patients further. Depression, anxiety, sleep problems, stress, medication overuse, and low degree of headache self-management were associated with poorer prognosis of chronic headache in randomized controlled trials (RCTs) and prospective cohorts as summarized in an American review [11]. It has long been known that headache syndromes are underdiagnosed and undertreated, especially migraine $[12,13]$. There are many possible reasons for that. Professional headache care needs to be better coordinated with general health practice [14,15] and is further challenged by variable access to headache specialists [16]. In a group of 1254 chronic migraine sufferers, $40 \%$ had consulted a headache specialist, but only $4.5 \%$ reported that they additionally received correct diagnosis and treatment [13]. Knowledge about how alternative specialist consultations using information and communication technology may be used to treat patients with difficult headache is limited. In less populated areas where a secondary health service such as a general neurological department is the only alternative to primary health care, telemedicine might be effective. The main hypothesis of this study was that treating chronic headache patients referred to a neurological department by using video consultations is not inferior to traditional face-to-face consultations.

\section{Methods}

\section{Study Design and Hypotheses}

The results from this study are based on post hoc analyses from a previous open-label randomized clinical trial where a larger group $(n=409)$ of heterogeneous headache patients referred from general practitioners (GPs) to specialists were assigned to either video or face-to-face (in-office) consultations to study cost, feasibility, and clinical aspects [17]. The trial was registered at ClinicalTrials.gov [NCT02270177]. The group of patients with chronic headache from that cohort were selected for this study to test the following primary hypothesis: providing treatment to chronic headache patients by specialist video consultations is noninferior to face-to-face specialist consultations with respect to 1 -year remission rate of chronic headache (change from $\geq 15$ to $<15$ headache days per month during the last 3 months). Secondary hypotheses were (1) patient satisfaction with specialist consultation, (2) frequency of chronic headache patients visiting GP for headache in the 12 months postconsultation, and (3) median number of headache-related consultations at GPs in the 12 months posttreatment, all end points postulated to be indifferent between the groups. The CONSORT-eHEALTH (Consolidated Standards of Reporting Trials of Electronic and Mobile Health Applications and Online TeleHealth) was used as a guide in describing the scientific study method [18].

\section{Study Population and Randomization}

Patients were consecutively identified, screened, randomized, and consulted for 2.5 years (September 30, 2012, to March 30, 2015). Of the included patients, $58.0 \%$ (233/402) of patients were classified to have chronic headache and included in the study (Figure 1). 
Figure 1. Flowchart of patients with chronic headache referred to neurologists from general practitioners for headache fulfilling the study inclusion criteria.

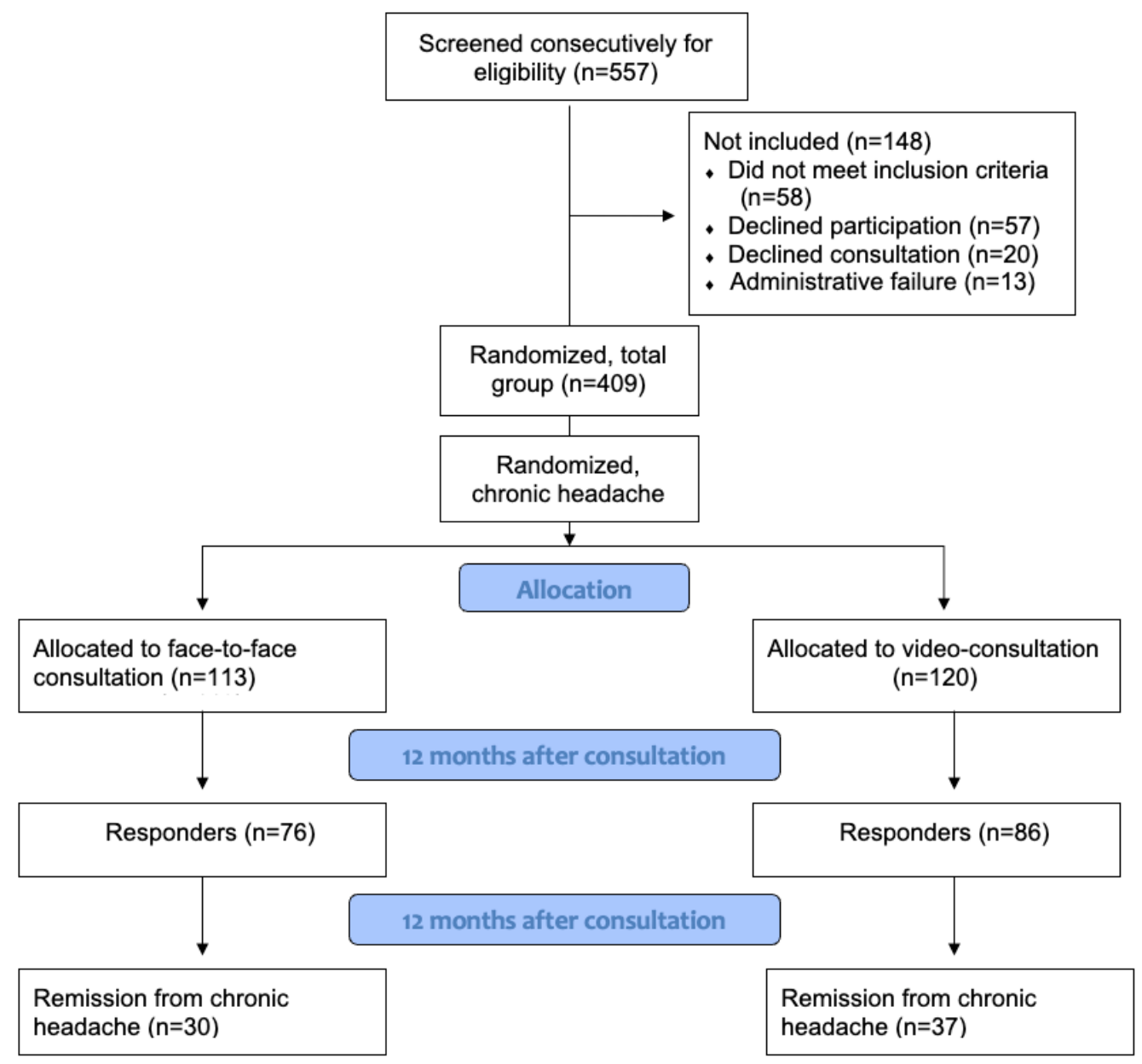

Selection criteria were as follows: (1) patients referred from GP to neurologist for headache, (2) fulfilling the classification criteria for chronic headache without evidence of secondary headache (ie, headaches classified as primary headache without specific causes [4] except patients with suspected medication overuse headache), (3) Norwegian speaking men and women aged 16 to 65 years, (4) not having visited a neurologist for headache within 2 years prior to consultation, and (5) waiting time from referral to consultation 4 months or less.

A nurse welcomed the participants at the entrance of the neurological department at the Troms $\varnothing$ University Hospital, checked the patient's self-administered prefilled forms and participation consent and called the randomization administrator at the hospital (Centre for Quality Improvement and Development). Participants were block-randomized by using an Rnd function in Access (Microsoft Corp), and thereafter guided to an examination room for face-to-face consultation (traditional group) or to the video conference room located next to the department (video group). Video consultations were performed by using a video conference system including a C40 Integrator package (Cisco Systems Inc) with dual display option and Touch Control Device for C Series, C40 Integrator Multisite (Cisco Systems Inc), Precision HD 1080P 12× camera (Cisco Systems Inc), X551S 55" LED (Sharp NEC Display Solutions of America Inc) monitor, ceiling microphones (Audio-Technica Inc), and JBL LSR2325P (Harman International Industries) active speakers installed in the video conference room providing 2-way video and audio communication between patient and specialist. The neurologists consulted the patients from 2 other offices via a EX60 unit (Cisco Systems Inc) with an in-touch panel. Traditional face-to-face consultations were performed in the same offices. The study nurse confirmed that the visual and audio devices worked and informed the patients about the location of the web camera and microphone and where to sit. The nurse also provided a short training and assured optimal communication with the specialist. Two experienced neurologists (KIM and SIB) performed clinical consultations without neurological examinations but with additional checklists for inclusion criteria, diagnostic classification, and a standardized interview which were developed before the trial without further development during the trial. Further details are published elsewhere [19].

\section{Data Collection and End Points}

Data were obtained by structured interview at baseline and via questionnaire at 1-year follow-up. The prefilled forms included a Headache Impact Test-6 (HIT-6) measuring 6 items of headache impact (pain, social, role and cognitive functioning, vitality, and psychological distress). Every question was answered by never, rarely, sometimes, very often, or always, and each answer scored $6,8,10,11$, or 13 points, respectively [20]. Pain intensity using a horizontal visual analog scale (VAS) 
ranging from 0 to $10(0=$ no pain, $10=$ worst possible pain $)$ was used in conjunction with HIT-6 [21]. Clinical and headache characteristics including comorbidity and diagnosis according to International Classification of Headache Disorders-2 [4] were recorded. Also, inaccurate headache diagnosis (ie, diagnostic disagreement between specialist and diagnoses reported in the electronic referral letter) were registered. The follow-up questionnaire recording demographics, clinical and headache characteristics, and end point variables was sent to the patients (with a reminder 2 weeks later to the nonresponders) either through an online survey service (Questback) or by postal letter. To classify chronic headache, the patients responded to number of headache days per month for the last 3 months.

Secondary end points were recorded from the patients' registration form as follows: "Where you satisfied with the consultation?" (yes or no), "Have you consulted your GP for headache after the specialist consultation?" (yes or no), and "Number of headache consultations with GP after the specialist consultation." Also, use of painkillers, triptans, and preventive headache drugs used in the last month were recorded.

\section{Ethics}

Oral and written consent were obtained from all participants before study entrance. The Norwegian National Committee for Medical and Health Research Ethics approved the study (number 2009/1430/REK).

\section{Statistical Analyses}

Data were analyzed with SPSS (version 27, IBM Corp). Descriptive variables are compared between the randomized groups and presented as mean and standard deviation or median and interquartile range in skewed distributed data (number of GP consultations). Consequently, comparisons between groups were analyzed by independent Student $t$ test or Mann-Whitney $U$ test, respectively; all 2-sided with $P<.05$ selected as level of statistical significance. Categorical variables were presented as numbers and percentages while groups were compared by using chi-square tests.

\section{Results}

Patients' characteristics were similar for both video and traditional consultations in all aspects including education and headache characteristics except for younger age in the video group (Table 1). A majority $(174 / 233,74.7 \%)$ had migraine as primary headache, and about one-third (79/233, 33.9\%) used analgesic drugs and/or triptans or other headache-specific medication (Table 1). Consultation duration was shorter in the video group (Table 1). Inaccurate headache diagnosis (diagnostic disagreement between specialist and diagnoses reported in the electronic referral letter) are presented in Table 2. Comparisons between the video group and the face-to-face group were insignificant with respect to renewed headache diagnosis and preventive treatment given by the specialist (Table 2). The specialist prescribed preventive medication to $50 \%$ to $70 \%$ of the patients, and the group with chronic headache remission was treated similarly regardless of consultation form in that respect (Table 2). The main outcome was $43.0 \%$ (37/86) 1-year chronic headache remission rate in the video group compared to $39.5 \%(30 / 76)$ in the traditional group $(P=.38$; Table 3$)$. Number and frequency of patients satisfied with consultations were $86.5 \%$ (32/37; video) and 93.3\% (28/30; face-to-face; $P=.25$; Table 3 ). GP consultations (numbers and frequencies of patients and median numbers of consultations) are presented in Table 3. More patients treated traditionally (16/30, 53.3\%) reported that they had consulted a GP for headache in the follow-up period (Table 3). No end points were otherwise statistically significantly different between the 2 groups. Neither were there any differences in changes in the HIT-6 and VAS scores from baseline to 1 -year assessment between the 2 groups (Table 2). 
Table 1. Clinical characteristics in randomized groups of patients referred to specialist for chronic headache consulted by video or traditionally.

\begin{tabular}{|c|c|c|c|c|c|c|}
\hline \multirow[t]{2}{*}{ Characteristic } & \multicolumn{3}{|c|}{ Chronic headache at baseline } & \multicolumn{3}{|c|}{ Remission from chronic headache at 12 months } \\
\hline & $\begin{array}{l}\text { Video } \\
(n=120)\end{array}$ & $\begin{array}{l}\text { Face-to-face } \\
(\mathrm{n}=113)\end{array}$ & $P$ value & $\begin{array}{l}\text { Video } \\
(\mathrm{n}=37)\end{array}$ & $\begin{array}{l}\text { Face-to-face } \\
(\mathrm{n}=30)\end{array}$ & $P$ value \\
\hline One-year response, n (\%) & $86(71.7)$ & $76(67.3)$ & .52 & $-{ }^{\mathrm{a}}$ & - & - \\
\hline Females, n (\%) & $86(71.7)$ & $84(74.3)$ & .66 & $30(72.1)$ & $21(70.0)$ & .39 \\
\hline Age (years), mean (SD) & $35.2(12.8)$ & $40.0(13.7)$ & .006 & $38.3(12.4)$ & $41.2(14.6)$ & .38 \\
\hline Education (years), mean (SD) & $13.2(2.9)$ & $14.0(3.1)$ & .07 & $13.3(2.7)$ & $13.9(3.0)$ & .42 \\
\hline Sick leave (headache, weeks), n (\%) & $42(35.0)$ & $43(38.1)$ & .68 & $11(29.7)$ & $12(40.0)$ & .58 \\
\hline Waiting time to specialist (days), mean (SD) & $59.0(29.0)$ & $55.2(26.1)$ & .29 & $58.7(25.5)$ & $46.9(23.5)$ & .06 \\
\hline Consultation duration (minutes), mean (SD) & $40.2(9.8)$ & $46.5(13.0)$ & $<.001$ & $41.0(8.1)$ & $45.8(8.8)$ & .02 \\
\hline BMI $\left(\mathrm{mg} / \mathrm{m}^{2}\right)$, mean $(\mathrm{SD})$ & $27.1(5.5)$ & $26.9(5.7)$ & .79 & $27.8(4.5)$ & $28.6(7.5)$ & .35 \\
\hline Obesity, BMI $\geq 30, \mathrm{n}(\%)$ & $31(25.8)$ & $29(25.7)$ & $>.99$ & $27(73.0)$ & $20(66.7)$ & .58 \\
\hline Without comorbidity, n (\%) & $62(51.7)$ & $52(46.0)$ & .54 & $18(48.6)$ & $13(43.3)$ & .81 \\
\hline Chronic neck pain, n (\%) & $56(46.7)$ & $57(50.4)$ & .60 & $20(54.1)$ & $14(46.7)$ & .63 \\
\hline Insomnia, n (\%) & $80(66.7)$ & $72(63.7)$ & .68 & $9(24.3)$ & $10(33.3)$ & .43 \\
\hline Hypertension, n (\%) & $11(9.2)$ & $17(15.0)$ & .23 & $5(13.5)$ & $4(13.3)$ & $>.99$ \\
\hline Age at headache onset (years), mean (SD) & $24.4(14.3)$ & $27.7(14.7)$ & .09 & $26.1(15.3)$ & $30.2(15.8)$ & .29 \\
\hline Headache duration (years), mean (SD) & $12.2(12.8)$ & $13.6(14.6)$ & .35 & $13.2(13.2)$ & $15.3(16.0)$ & .58 \\
\hline \multicolumn{7}{|l|}{ Chronic headache subtype $^{b}$, n (\%) } \\
\hline Migraine & $90(75.0)$ & $84(74.3)$ & $>.99$ & $31(83.8)$ & $23(76.6)$ & .79 \\
\hline Tension-type & $23(19.2)$ & $28(24.8)$ & .34 & $6(16.2)$ & $6(20.0)$ & - \\
\hline Other & $7(5.8)$ & $1(0.9)$ & - & $0(0)$ & $1(3.3)$ & - \\
\hline Medication $\geq 15$ days/month ${ }^{\mathrm{c}}, \mathrm{n}(\%)$ & $39(32.5)$ & $40(35.4)$ & .68 & $8(21.6)$ & $3(10.0)$ & - \\
\hline
\end{tabular}

${ }^{\mathrm{a}}$ Not applicable.

${ }^{\mathrm{b}}$ Most prominent headache subtype given by specialist.

${ }^{\mathrm{c}}$ Use of painkillers and/or triptans $\geq 15$ days per month last 3 month.

Table 2. Diagnostic changes and preventive chronic headache treatment given by neurologist. Comparisons between groups of patients randomized to either video or traditional consultations.

\begin{tabular}{|c|c|c|c|c|c|c|}
\hline \multirow[t]{2}{*}{ Variable } & \multicolumn{3}{|c|}{ Persistent chronic headache at 12 months } & \multicolumn{3}{|c|}{ Remission from chronic headache at 12 months } \\
\hline & $\begin{array}{l}\text { Video } \\
(n=49)\end{array}$ & $\begin{array}{l}\text { Face-to-face } \\
(\mathrm{n}=46)\end{array}$ & $P$ value & $\begin{array}{l}\text { Video } \\
(n=37)\end{array}$ & $\begin{array}{l}\text { Face-to-face } \\
(\mathrm{n}=30)\end{array}$ & $P$ value \\
\hline New headache diagnosis, $\mathrm{n}(\%)$ & $15(30.6)$ & $9(19.6)$ & .25 & $9(24.3)$ & $9(30.0)$ & .78 \\
\hline Preventive treatment, $\mathbf{n}(\%)$ & $26(53.1)$ & $29(63.0)$ & .41 & $26(70.3)$ & $21(70.0)$ & $>.99$ \\
\hline Antihypertensive & $9(18.4)$ & $5(10.9)$ & $-^{\mathrm{a}}$ & $9(24.3)$ & $3(10.0)$ & - \\
\hline Antiepileptic & $6(12.2)$ & $7(15.1)$ & - & $7(18.8)$ & $6(20.0)$ & - \\
\hline Antidepressant & $11(22.5)$ & $17(37.0)$ & - & $10(27.0)$ & $12(40.0)$ & - \\
\hline Triptans, n (\%) & $19(38.8)$ & $14(30.4)$ & .55 & $11(29.7)$ & $6(20.0)$ & .41 \\
\hline
\end{tabular}

${ }^{\mathrm{a}}$ Not applicable. 
Table 3. Remission rates from chronic headache (primary end point), patient's satisfaction with consultation and general practitioner consultations (secondary end points), headache-related symptoms, and therapy in the 12 months after specialist consultation. Patients randomized to either video or traditional consultations.

\begin{tabular}{|c|c|c|c|c|c|c|}
\hline \multirow[t]{2}{*}{ Variables } & \multicolumn{3}{|c|}{ Persistent chronic headache at 12 months } & \multicolumn{3}{|c|}{ Remission from chronic headache at 12 months } \\
\hline & $\begin{array}{l}\text { Video } \\
(\mathrm{n}=49)\end{array}$ & $\begin{array}{l}\text { Face-to-face } \\
(\mathrm{n}=46)\end{array}$ & $P$ value & $\begin{array}{l}\text { Video } \\
(\mathrm{n}=37)\end{array}$ & $\begin{array}{l}\text { Face-to-face } \\
(\mathrm{n}=30)\end{array}$ & $P$ value \\
\hline Remission rate from $\mathrm{CH}^{\mathrm{a}}(\%)^{\mathrm{b}}$ & $-^{c}$ & - & - & $37 / 86(43.0)$ & $30 / 76(39.5)$ & .38 \\
\hline Persistent $\mathrm{CH}(\%)^{\mathrm{b}}$ & $49 / 86(57.0)$ & $46 / 76(60.5)$ & .38 & - & - & - \\
\hline Patient satisfaction with consultation, $\mathrm{n}(\%)$ & $42(85.7)$ & $41(89.1)$ & .41 & $32(86.5)$ & $28(93.3)$ & .25 \\
\hline $\mathrm{GP}^{\mathrm{d}}$ consultations, $\mathrm{n}(\%)$ & $29(59.2)$ & $20(43.5)$ & .12 & $11(29.7)$ & $16(53.3)$ & .03 \\
\hline GP consultations, median (IQR range) & $2(0-11)$ & $1(0-11)$ & .04 & $1(0-13)$ & $1.5(0-15)$ & .19 \\
\hline $\mathrm{HIT}^{\mathrm{e}}-6$, baseline, mean (SD) & $64.0(5.6)$ & $64.9(4.6)$ & .38 & $66.0(3.9)$ & $63.7(6.4)$ & .09 \\
\hline HIT-6 after 1 year, mean (SD) & $58.3(8.8)$ & $61.6(7.8)$ & .10 & $59.9(10.5)$ & $59.2(8.2)$ & .98 \\
\hline$\Delta$ HIT-6, mean (SD) & $5.7(9.3)$ & $3.3(8.7)$ & .08 & $5.5(12.4)$ & $5.8(9.6)$ & .92 \\
\hline $\mathrm{VAS}^{\mathrm{f}}$, baseline, mean (SD) & $6.9(2.3)$ & $6.9(2.1)$ & .95 & $7.0(2.1)$ & $6.8(2.0)$ & .66 \\
\hline VAS after 1 year, mean (SD) & $5.2(2.8)$ & $6.6(2.0)$ & .02 & $5.3(2.8)$ & $5.2(3.2)$ & .94 \\
\hline$\Delta \mathrm{VAS}$, mean $(\mathrm{SD})$ & $1.7(3.8)$ & $0.3(3.5)$ & .01 & $1.7(3.3)$ & $1.6(3.5)$ & .80 \\
\hline Analgesic use, n (\%) & $38(77.6)$ & $39(84.8)$ & .44 & $34(91.9)$ & $29(96.7)$ & .62 \\
\hline Medication $\geq 15$ days/month ${ }^{\mathrm{g}}, \mathrm{n}(\%)$ & $27(55.1)$ & $23(50.0)$ & .48 & $8(21.6)$ & $3(10.0)$ & - \\
\hline
\end{tabular}

${ }^{\mathrm{a}} \mathrm{CH}$ : chronic headache.

${ }^{\mathrm{b}}$ Calculated by using response rates (per protocol analyses) as reference.

${ }^{\mathrm{c}}$ Not applicable.

${ }^{\mathrm{d}} \mathrm{GP}$ : general practitioner.

${ }^{\mathrm{e}} \mathrm{HIT}$ : headache impact test.

f VAS: visual analog scale.

${ }^{\mathrm{g}}$ Use of painkillers and/or triptans $\geq 15$ days per month last 3 months.

When taken data from the groups together (pooled data), the comparisons between baseline and status after 12 months were as follows: remission rate from chronic headache was $41.4 \%$ (67/162) and numbers visiting GPs were 30.2\% (49/162) of those with persisting chronic headache and $40.3 \%$ (27/67) in the chronic headache remission group $(P=.41)$. Median numbers of GP consultations were 1.0 (IQR 0-15) and 2.0 (IQR 0-11), respectively $(P=.25)$. The rate of participants using analgesic medication or triptans $\geq 15$ days per month declined from $52.6 \%$ (50/95) to $16.4 \%(11 / 67) 1$-year post consultation.

\section{Discussion}

\section{Principal Findings}

By managing new referred chronic headache patients at a secondary neurological center, the 1-year results from this post hoc RCT showed that consulting a neurological specialist by using video were equivalent to face-to-face consultations. Thus, we found no significant differences in remission rate from chronic headache, patient satisfaction with consultation, or GP visits due to headache conducted in the 1-year follow-up period. This study provides evidence to support specialist video consultations as a good alternative to face-to-face consultations in treating patients with chronic headache.

\section{Comparison With Prior Work}

There are no previous studies comparing consultation forms in treating chronic headache by a specialist, but in an earlier RCT the group of chronic headache patients randomized to an internet-delivered self-managing relaxation program $(n=39)$ improved by $47 \%$ on measures of self-reported headache symptoms compared to an equivalent control group recruited from the waiting list with symptom monitoring only [22]. That study documents the usefulness of communicating via electronic devices as an alternative to face-to-face consultations in treating difficult headache such as chronic headache in line with this study. Likewise, the 1-year treatment response is comparable between the studies (47\% vs $43 \%$ ) despite different treatment methods and outcomes [22]. A smaller RCT by Friedman et al [23] randomized 18 patients with severe migraine to video consultations and 12 to in-office visits in a tertiary headache center. Improvement in headache burden and number of headache days were not different between the groups, and the authors concluded that video consultations were as effective as in-office visits. Furthermore, the consultation time was shorter in the telemedicine cohort as in this study (Table 1) indicating that telemedicine is effective for physicians in treating difficult headache [23]. 
In our study, approximately $40 \%$ of the chronic headache patients had remitted 1-year postconsultation while about $60 \%$ persisted with chronic headache. This rate of remission is somewhat lower than a previous longitudinal study that showed a $40 \%$ persistent rate at 1 year and $25 \%$ at 2-year follow-up [24]. Medication overuse was associated with chronicity in that study, which is also indicated here, as the rate of participants using analgesic medication or triptans $\geq 15$ days per month declined from $52.6 \%$ to $16.4 \%$. Similar findings are also demonstrated in population-based studies [25]. RCTs as a method to investigate different neurological outpatient management are in general few [26,27], but use of telemedicine was equivalent to face-to-face consultations with specialist as far as number of consultations [28]. Teleneurology is nevertheless widely used in clinical practice [29-31] with favorable results from the patient perspective (time- and money-saving, communication, perceiving good care, and future preference) [31,32]. From a specialist point of view $(n=135$ specialists), headache and follow-up consultations were well suited for telemedicine [33].

In general, RCTs in eHealth are few despite occurrence of the COVID-19 pandemic situation, which has demonstrated a need for more evidence-based knowledge about the use of digital health technology in evaluating treatment effect, safety, and other aspects of patient management [34-37]. Patient education programs [38,39]; evaluation of psychological distress using teletechnology in diabetes [40]; use of mobile in suboptimal health [41], surgery care, and follow-up [42-44]; aphasia [44]; HIV consultations [38]; cancer symptom monitoring [45]; motor and cognitive function in stroke [46]; and COVID-19 follow-up [47] are areas where RCTs are used. Moreover, this study agrees with previous telemedicine RCTs in the same area reporting positive outcomes in treating diabetic foot ulcer [48] and in a follow-up study of orthopedic patients [49]. Thus, the RCT design is the main advantage of this study, especially since it is the first one to compare consultation forms with specialist in chronic headache where one treatment arm is based on teletechnology.

\section{Limitations}

This post hoc study containing a 53\% sample of the original cohort of headache sufferers may be prone to statistical type 2 failure due to risk of underpowered sample size, although the video and traditional consultation groups were similar with respect to group sizes and most of the social and clinical characteristics reflecting a design resistant to selection bias. Moreover, such a study lacks a placebo group and blinding, which would have optimized the evidence further. Awareness of the fact that this study compares different consultation forms and not specific treatment options should be emphasized. Interim analyses comparing additional clinical information between patient groups within the 1-year follow-up period might extend the knowledge about patient experiences with video consultations and should be performed in future studies. Additionally, consecutively including patients from clinical practice and a relatively low dropout rate accounts for acceptable generalizability.

\section{Conclusions}

This RCT of video consultations for new referrals of chronic headache patients demonstrated that chronic headache remission rate, patient satisfaction with specialist consultation, and GP consultations for headache performed during follow-up were equivalent between the video group and the face-to-face group. This study adds to the documentation of eHealth in consulting headache patients by specialist.

\section{Acknowledgments}

Jorun Willumsen, Anna-Kirsti Kvitnes, Marlen Lauritsen, Nora Bekkelund, Karin Flatekval Eines, Torill Erdahl, Marianne Røst, and Grethe Berg Johnsen are acknowledged for skillful help with patient logistics and data acquisition. The publication charges for this article have been funded by a grant from the publication fund of the Arctic University of Norway. The Northern Norway Regional Health Authority funded this study.

\section{Authors' Contributions}

SIB contributed to the conception and design, data collection, statistical analysis, and interpretation of data, wrote the article, and approved the final version. KIM contributed with data collection, revision of the manuscript, and approval of the final version.

\section{Conflicts of Interest}

None declared.

\section{Multimedia Appendix 1}

CONSORT-eHEALTH checklist (V 1.6.1).

[PDF File (Adobe PDF File), 239 KB-Multimedia Appendix 1]

\section{References}

1. Natoli JL, Manack A, Dean B, Butler Q, Turkel CC, Stovner L, et al. Global prevalence of chronic migraine: a systematic review. Cephalalgia 2010 May;30(5):599-609. [doi: 10.1111/j.1468-2982.2009.01941.x] [Medline: 19614702]

2. Schwartz BS, Stewart WF, Simon D, Lipton RB. Epidemiology of tension-type headache. JAMA 1998 Feb 04;279(5):381-383. [doi: 10.1001/jama.279.5.381] [Medline: 9459472] 
3. Buse DC, Manack AN, Fanning KM, Serrano D, Reed ML, Turkel CC, et al. Chronic migraine prevalence, disability, and sociodemographic factors: results from the American Migraine Prevalence and Prevention Study. Headache 2012;52(10):1456-1470. [doi: 10.1111/j.1526-4610.2012.02223.x] [Medline: 22830411]

4. Headache Classification Committee of the International Headache Society (IHS). The International Classification of Headache Disorders, 3rd edition (beta version). Cephalalgia 2013 Jul;33(9):629-808. [doi: 10.1177/0333102413485658] [Medline: 23771276]

5. Reuter U. GBD 2016: still no improvement in the burden of migraine. Lancet Neurol 2018 Nov;17(11):929-930 [FREE Full text] [doi: 10.1016/S1474-4422(18)30360-0] [Medline: 30353862]

6. GBD 2016 Headache Collaborators. Global, regional, and national burden of migraine and tension-type headache, 1990-2016: a systematic analysis for the Global Burden of Disease Study 2016. Lancet Neurol 2018 Nov;17(11):954-976 [FREE Full text] [doi: 10.1016/S1474-4422(18)30322-3] [Medline: 30353868]

7. Karimi L, Wijeratne T, Crewther SG, Evans AE, Ebaid D, Khalil H. The migraine-anxiety comorbidity among migraineurs: a systematic review. Front Neurol 2020;11:613372 [FREE Full text] [doi: 10.3389/fneur.2020.613372] [Medline: 33536997]

8. Scher AI, Buse DC, Fanning KM, Kelly AM, Franznick DA, Adams AM, et al. Comorbid pain and migraine chronicity: The Chronic Migraine Epidemiology and Outcomes Study. Neurology 2017 Aug 01;89(5):461-468 [FREE Full text] [doi: 10.1212/WNL.0000000000004177] [Medline: 28679597]

9. Messali A, Sanderson JC, Blumenfeld AM, Goadsby PJ, Buse DC, Varon SF, et al. Direct and indirect costs of chronic and episodic migraine in the united states: a web-based survey. Headache 2016 Feb;56(2):306-322. [doi: 10.1111/head.12755] [Medline: 26833083]

10. Von Korff M, Stewart WF, Simon DJ, Lipton RB. Migraine and reduced work performance: a population-based diary study. Neurology 1998 Jun;50(6):1741-1745. [doi: 10.1212/wnl.50.6.1741] [Medline: 9633720]

11. Potter R, Probyn K, Bernstein C, Pincus T, Underwood M, Matharu M. Diagnostic and classification tools for chronic headache disorders: a systematic review. Cephalalgia 2019 May;39(6):761-784 [FREE Full text] [doi:

10.1177/0333102418806864] [Medline: 30335472]

12. Cevoli S, D'Amico D, Martelletti P, Valguarnera F, Del Bene E, De Simone R, et al. Underdiagnosis and undertreatment of migraine in Italy: a survey of patients attending for the first time 10 headache centres. Cephalalgia 2009 Dec;29(12):1285-1293. [doi: 10.1111/j.1468-2982.2009.01874.x] [Medline: 19438916 ]

13. Dodick DW, Loder EW, Manack Adams A, Buse DC, Fanning KM, Reed ML, et al. Assessing barriers to chronic migraine consultation, diagnosis, and treatment: results from the Chronic Migraine Epidemiology and Outcomes (CaMEO) Study. Headache 2016 May;56(5):821-834 [FREE Full text] [doi: 10.1111/head.12774] [Medline: 27143127]

14. Katsarava Z, Mania M, Lampl C, Herberhold J, Steiner TJ. Poor medical care for people with migraine in Europe: evidence from the Eurolight study. J Headache Pain 2018 Feb 01;19(1):10 [FREE Full text] [doi: 10.1186/s10194-018-0839-1] [Medline: 29392600]

15. Ryvlin P, Skorobogatykh K, Negro A, Sanchez-De La Rosa R, Israel-Willner H, Sundal C, et al. Current clinical practice in disabling and chronic migraine in the primary care setting: results from the European My-LIFE anamnesis survey. BMC Neurol 2021 Jan 04;21(1):1 [ [FREE Full text] [doi: 10.1186/s12883-020-02014-6] [Medline: 33390161]

16. Tassorelli C, Farm I, Kettinen H, de la Torre ER, Stretenovic S, Thomas W, et al. Access to care-an unmet need in headache management? J Headache Pain 2014;15:20 [FREE Full text] [doi: 10.1186/1129-2377-15-20] [Medline: 24742114]

17. Müller KI, Alstadhaug KB, Bekkelund SI. Acceptability, feasibility, and cost of telemedicine for nonacute headaches: a randomized study comparing video and traditional consultations. J Med Internet Res 2016 May 30;18(5):e140 [FREE Full text] [doi: 10.2196/jmir.5221] [Medline: 27241876]

18. Eysenbach G, CONSORT-EHEALTH Group. CONSORT-EHEALTH: improving and standardizing evaluation reports of Web-based and mobile health interventions. J Med Internet Res 2011 Dec 31;13(4):e126 [FREE Full text] [doi: 10.2196/jmir.1923] [Medline: 22209829]

19. Müller KI, Alstadhaug KB, Bekkelund SI. A randomized trial of telemedicine efficacy and safety for nonacute headaches. Neurology 2017 Jul 11;89(2):153-162 [FREE Full text] [doi: 10.1212/WNL.0000000000004085] [Medline: 28615434]

20. Yang M, Rendas-Baum R, Varon SF, Kosinski M. Validation of the Headache Impact Test (HIT-6 ${ }^{\text {TM }}$ ) across episodic and chronic migraine. Cephalalgia 2011 Feb;31(3):357-367 [FREE Full text] [doi: 10.1177/0333102410379890] [Medline: 20819842]

21. Lundqvist C, Benth JS, Grande RB, Aaseth K, Russell MB. A vertical VAS is a valid instrument for monitoring headache pain intensity. Cephalalgia 2009 Oct;29(10):1034-1041 [FREE Full text] [doi: 10.1111/j.1468-2982.2008.01833.x] [Medline: 19735531]

22. Devineni T, Blanchard EB. A randomized controlled trial of an internet-based treatment for chronic headache. Behav Res Ther 2005 Mar;43(3):277-292. [doi: 10.1016/j.brat.2004.01.008] [Medline: 15680926 ]

23. Friedman DI, Rajan B, Seidmann A. A randomized trial of telemedicine for migraine management. Cephalalgia 2019 Oct;39(12):1577-1585. [doi: 10.1177/0333102419868250] [Medline: $\underline{31450969]}$

24. Wang S, Fuh J, Lu S, Juang K. Outcomes and predictors of chronic daily headache in adolescents: a 2-year longitudinal study. Neurology 2007 Feb 20;68(8):591-596. [doi: 10.1212/01.wnl.0000252800.82704.62] [Medline: 17182975] 
25. Hagen K, Kristoffersen ES, Winsvold BS, Stovner LJ, Zwart J. Remission of chronic headache: an 11-year follow-up study. Data from the Nord-Trøndelag Health Surveys 1995-1997 and 2006-2008. Cephalalgia 2018 Dec;38(14):2026-2034. [doi: 10.1177/0333102418769940] [Medline: 29629599]

26. Wechsler LR. Advantages and limitations of teleneurology. JAMA Neurol 2015 Mar;72(3):349-354. [doi: 10.1001/jamaneurol.2014.3844] [Medline: 25580942]

27. Wilkinson JR, Spindler M, Wood SM, Marcus SC, Weintraub D, Morley JF, et al. High patient satisfaction with telehealth in Parkinson disease: a randomized controlled study. Neurol Clin Pract 2016 Jun;6(3):241-251 [FREE Full text] [doi: 10.1212/CPJ.0000000000000252] [Medline: 27347441]

28. Chua R, Craig J, Esmonde T, Wootton R, Patterson V. Telemedicine for new neurological outpatients: putting a randomized controlled trial in the context of everyday practice. J Telemed Telecare 2002;8(5):270-273. [doi: 10.1177/1357633X0200800505] [Medline: 12396855]

29. George BP, Scoglio NJ, Reminick JI, Rajan B, Beck CA, Seidmann A, et al. Telemedicine in leading US neurology departments. Neurohospitalist 2012 Oct 17;2(4):123-128 [FREE Full text] [doi: 10.1177/1941874412450716] [Medline: $\underline{23983876]}$

30. Yurkiewicz IR, Lappan CM, Neely ET, Hesselbrock RR, Girard PD, Alphonso AL, et al. Outcomes from a US military neurology and traumatic brain injury telemedicine program. Neurology 2012 Sep 18;79(12):1237-1243. [doi: 10.1212/WNL.0b013e31826aac33] [Medline: 22955133]

31. Davis LE, Coleman J, Harnar J, King MK. Teleneurology: successful delivery of chronic neurologic care to 354 patients living remotely in a rural state. Telemed J E Health 2014 May;20(5):473-477. [doi: 10.1089/tmj.2013.0217] [Medline: 24617919]

32. Davis LE, Harnar J, LaChey-Barbee LA, Pirio Richardson S, Fraser A, King MK. Using teleneurology to deliver chronic neurologic care to rural veterans: analysis of the first 1,100 patient visits. Telemed J E Health 2019 Apr;25(4):274-278. [doi: 10.1089/tmj.2018.0067] [Medline: 30016207]

33. Kristoffersen ES, Sandset EC, Winsvold BS, Faiz KW, Storstein AM. Experiences of telemedicine in neurological out-patient clinics during the COVID-19 pandemic. Ann Clin Transl Neurol 2021 Feb;8(2):440-447 [FREE Full text] [doi: 10.1002/acn3.51293] [Medline: 33377609]

34. Gunasekeran DV, Tseng RMWW, Tham Y, Wong TY. Applications of digital health for public health responses to COVID-19: a systematic scoping review of artificial intelligence, telehealth and related technologies. NPJ Digit Med 2021 Feb 26;4(1):40 [FREE Full text] [doi: 10.1038/s41746-021-00412-9] [Medline: 33637833]

35. Golinelli D, Boetto E, Carullo G, Nuzzolese AG, Landini MP, Fantini MP. Adoption of digital technologies in health care during the COVID-19 pandemic: systematic review of early scientific literature. J Med Internet Res 2020 Nov 06;22(11):e22280 [FREE Full text] [doi: 10.2196/22280] [Medline: 33079693]

36. Svendsen MT, Tiedemann SN, Andersen KE. Pros and cons of eHealth: a systematic review of the literature and observations in Denmark. SAGE Open Med 2021;9:20503121211016179 [FREE Full text] [doi: 10.1177/20503121211016179] [Medline: $\underline{34046178]}$

37. Angus-Leppan H, Guiloff AE, Benson K, Guiloff RJ. Navigating migraine care through the COVID-19 pandemic: an update. J Neurol 2021 May 17:1-8 [FREE Full text] [doi: 10.1007/s00415-021-10610-w] [Medline: 34002281]

38. Hickey MD, Sergi F, Zhang K, Spinelli MA, Black D, Sola C, et al. Pragmatic randomized trial of a pre-visit intervention to improve the quality of telemedicine visits for vulnerable patients living with HIV. J Telemed Telecare 2020 Dec 20:1357633X20976036. [doi: 10.1177/1357633X20976036] [Medline: 33342328]

39. Allida S, Du H, Xu X, Prichard R, Chang S, Hickman LD, et al. mHealth education interventions in heart failure. Cochrane Database Syst Rev 2020 Jul 02;7:CD011845 [FREE Full text] [doi: 10.1002/14651858.CD011845.pub2] [Medline: 32613635]

40. Alessi J, de Oliveira GB, Franco DW, Becker AS, Knijnik CP, Kobe GL, et al. Telehealth strategy to mitigate the negative psychological impact of the COVID-19 pandemic on type 2 diabetes: a randomized controlled trial. Acta Diabetol 2021 Jul;58(7):899-909. [doi: 10.1007/s00592-021-01690-1] [Medline: 33723649]

41. Baek Y, Jeong K, Lee S, Kim H, Seo B, Jin H. Feasibility and effectiveness of assessing subhealth using a mobile health management app (MibyeongBogam) in early middle-aged koreans: randomized controlled trial. JMIR Mhealth Uhealth 2021 Aug 19;9(8):e27455 [FREE Full text] [doi: 10.2196/27455] [Medline: $\underline{\text { 34420922] }}$

42. Binder EF, Christensen JC, Stevens-Lapsley J, Bartley J, Berry SD, Dobs AS, et al. A multi-center trial of exercise and testosterone therapy in women after hip fracture: design, methods and impact of the COVID-19 pandemic. Contemp Clin Trials 2021 May;104:106356. [doi: 10.1016/j.cct.2021.106356] [Medline: 33716173]

43. Kolcun JPG, Ryu WHA, Traynelis VC. Systematic review of telemedicine in spine surgery. J Neurosurg Spine 2020 Oct 30:1-10. [doi: 10.3171/2020.6.SPINE20863] [Medline: 33126219]

44. Harkey K, Kaiser N, Zhao J, Hetherington T, Gutnik B, Matthews BD, et al. Postdischarge virtual visits for low-risk surgeries: a randomized noninferiority clinical trial. JAMA Surg 2021 Mar 01;156(3):221-228. [doi:

10.1001/jamasurg.2020.6265] [Medline: 33439221]

45. Maguire R, McCann L, Kotronoulas G, Kearney N, Ream E, Armes J, et al. Real time remote symptom monitoring during chemotherapy for cancer: European multicentre randomised controlled trial (eSMART). BMJ 2021 Jul 21;374:n1647 [FREE Full text] [doi: 10.1136/bmj.n1647] [Medline: 34289996] 
46. Ozen S, Senlikci HB, Guzel S, Yemisci OU. Computer game assisted task specific exercises in the treatment of motor and cognitive function and quality of life in stroke: a randomized control study. J Stroke Cerebrovasc Dis 2021 Sep;30(9):105991. [doi: 10.1016/j.jstrokecerebrovasdis.2021.105991] [Medline: $\underline{34293643]}$

47. Rodriguez-Blanco C, Gonzalez-Gerez JJ, Bernal-Utrera C, Anarte-Lazo E, Perez-Ale M, Saavedra-Hernandez M. Short-term effects of a conditioning telerehabilitation program in confined patients affected by COVID-19 in the acute phase. a pilot randomized controlled trial. Medicina (Kaunas) 2021 Jul 03;57(7):1 [FREE Full text] [doi: 10.3390/medicina57070684] [Medline: 34356965]

48. Iversen MM, Igland J, Smith-Strøm H, Østbye T, Tell GS, Skeie S, et al. Effect of a telemedicine intervention for diabetes-related foot ulcers on health, well-being and quality of life: secondary outcomes from a cluster randomized controlled trial (DiaFOTo). BMC Endocr Disord 2020 Oct 21;20(1):157 [FREE Full text] [doi: 10.1186/s12902-020-00637-x] [Medline: 33087074$]$

49. Buvik A, Bugge E, Knutsen G, Småbrekke A, Wilsgaard T. Patient satisfaction with remote orthopaedic consultation by using telemedicine: a randomised controlled trial. J Telemed Telecare 2018 Jan 01:1357633X18783921. [doi: 10.1177/1357633X18783921] [Medline: 29973130]

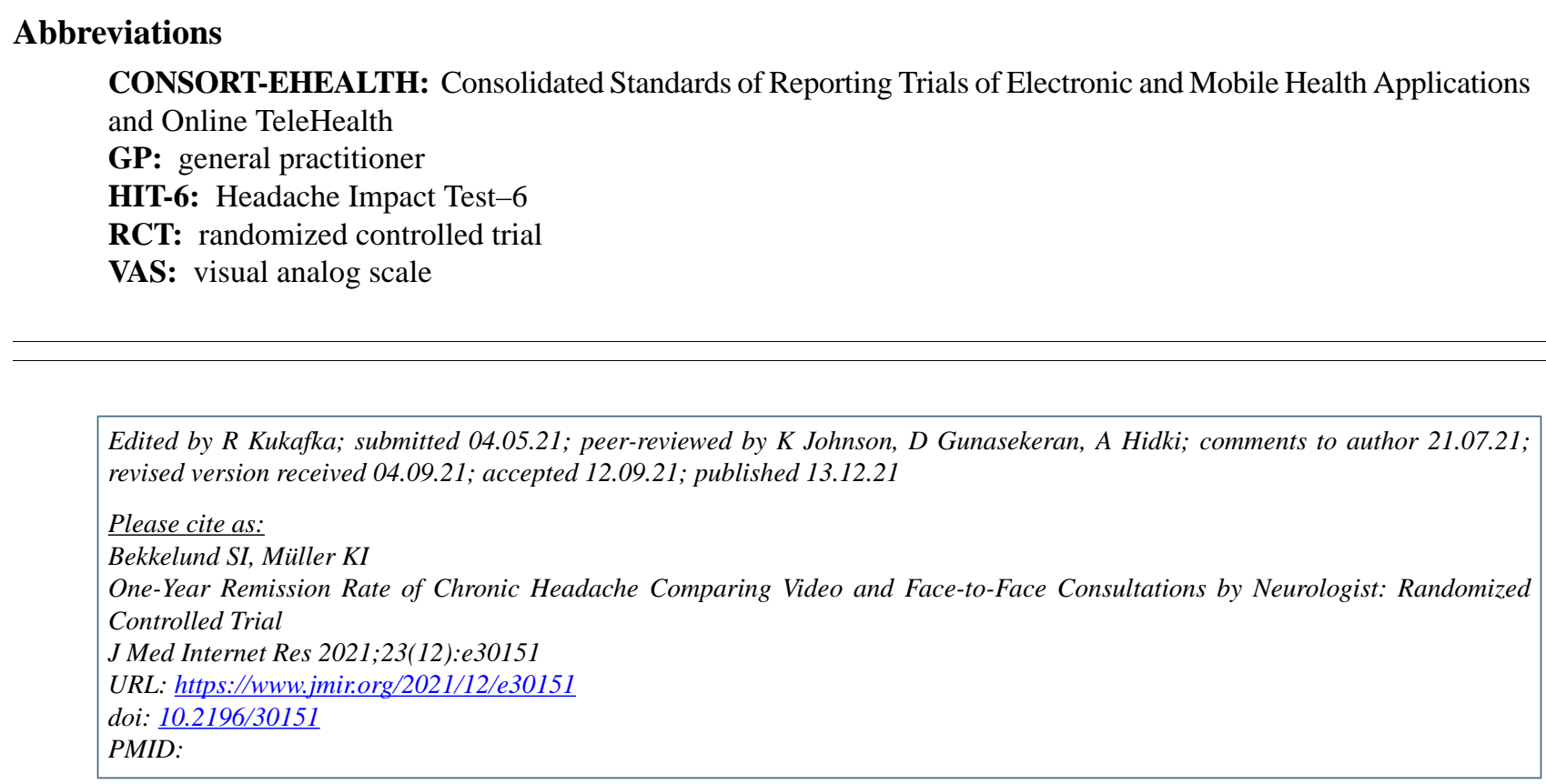

(CSvein Ivar Bekkelund, Kai Ivar Müller. Originally published in the Journal of Medical Internet Research (https://www.jmir.org), 13.12.2021. This is an open-access article distributed under the terms of the Creative Commons Attribution License (https://creativecommons.org/licenses/by/4.0/), which permits unrestricted use, distribution, and reproduction in any medium, provided the original work, first published in the Journal of Medical Internet Research, is properly cited. The complete bibliographic information, a link to the original publication on https://www.jmir.org/, as well as this copyright and license information must be included. 